\title{
Utilization of the state led public private partnership program "Chiranjeevi Yojana" to promote facility births in Gujarat, India: a cross sectional community based study
}

Sandul Yasobant ${ }^{1 *}$ (D, Kranti Suresh Vora ${ }^{1}$, Hemant Deepak Shewade ${ }^{2}$, Kristi Sidney Annerstedt ${ }^{3}$, Petros Isaakidis ${ }^{4}$, Dileep V. Mavalankar ${ }^{1}$, Nishith B. Dholakia ${ }^{5}$ and Ayesha De Costa ${ }^{3}$

\begin{abstract}
Background: "Chiranjeevi Yojana (CY)", a state-led large-scale demand-side financing scheme (DSF) under publicprivate partnership to increase institutional delivery, has been implemented across Gujarat state, India since 2005. The scheme aims to provide free institutional childbirth services in accredited private health facilities to women from socially disadvantaged groups (eligible women). These services are paid for by the state to the private facility with the intention of service being free to the user. This community-based study estimates CY uptake among eligible women and explores factors associated with non-utilization of the CY program.
\end{abstract}

Methods: This was a community-based cross sectional survey of eligible women who gave birth between January and July 2013 in 142 selected villages of three districts in Gujarat. A structured questionnaire was administered by trained research assistant to collect information on socio-demographic details, pregnancy details, details of childbirth and out-of-pocket (OOP) expenses incurred. A multivariable inferential analysis was done to explore the factors associated with non-utilization of the CY program.

Results: Out of 2,143 eligible women, 559 (26\%) gave birth under the CY program. A further $436(20 \%)$ delivered at free public facilities, 713(33\%) at private facilities (OOP payment) and 435(20 \%) at home. Eligible women who belonged to either scheduled tribe or poor [aOR $=3.1,95 \% \mathrm{Cl}: 2.4-3.8]$ or having no formal education $[\mathrm{aOR}=1.6$, $95 \%$ Cl:1.1, 2.2] and who delivered by C-section [aOR $=2.1,95 \% \mathrm{Cl}: 1.2,3.8]$ had higher odds of not utilizing CY program. Of births at CY accredited facilities $(n=924)$, non-utilization was $40 \%(n=365)$ mostly because of lack of required official documentation that proved eligibility ( $72 \%$ of eligible non-users). Women who utilized the CY program overall paid more than women who delivered in the free public facilities.

Conclusion: Uptake of the CY among eligible women was low after almost a decade of implementation. Community level awareness programs are needed to increase participation among eligible women. OOP expense was incurred among who utilized CY program; this may be a factor associated with non-utilization in next pregnancy which needs to be studied. There is also a need to ensure financial protection of women who have C-section.

Keywords: Maternal mortality, Chiranjeevi Yojana, Demand side financing, Utilization, Institutional delivery, India

\footnotetext{
* Correspondence: dryasobant@gmail.com

'Indian Institute of Public Health-Gandhinagar, Sardar Patel Institute Campus,

Drive-in-Road, Ahmedabad, Gujarat 380054, India

Full list of author information is available at the end of the article
} 


\section{Background}

In the past two decades several low-and middle-income countries have implemented demand-side financial incentives (DSF) to improve healthcare service utilization and health-related behavior [1], specifically to address the maternal and child health related Millennium Development Goals (MDG-5) [2, 3]. MDG-5 and the Sustainable Development Goal (SDG-3.1) include the promotion of institutional deliveries as a strategy to reduce maternal mortality [4]. DSF programs incentivize a specified group to adapt a service or alter a behavior to improve health, education or help alleviate poverty. In maternal health, two of the most common types are voucher schemes where all or part of the cost of services are paid for, and cash transfer schemes where women are reimbursed for the costs of maternity services $[2,3,5]$.

To increase the number of institutional deliveries, particularly among women from socially disadvantaged groups (i.e. women who lived below the poverty line or came from tribal castes-eligible women) in whom maternal deaths are more likely to occur, the Government of Gujarat, a large state of India, in 2005 implemented a large state-led DSF scheme in the form of a publicprivate-partnership (PPP), Chiranjeevi Yojana (CY). The CY (long life) was developed in response to an acute shortage of qualified obstetricians/gynecologists in the public health sector in Gujarat as most practiced in the private sector, where they received out of pocket payments for services rendered [6]. Under the CY program, eligible mothers could be beneficiaries by giving birth at an accredited private facility within the district, (led by a qualified obstetrician and free intra-partum care including emergency obstetric care) on presentation of a Government issued proof of poverty or tribal status. The government paid Indian Rupees (INR) 4000 per delivery (approximately \$67) directly to the private facility irrespective of the type of birth i.e. vaginal or cesarean section (C-section). To date, about a million births have occurred under CY [7-9].

While overall institutional deliveries significantly increased from $58 \%$ in 2004-06 to $95 \%$ in 2010-12 [10-12], public sector deliveries rose only marginally from $24 \%$ in 2001 to $29 \%$ in 2010, indicating a large shift of childbirths occurring at home to the private sector [12]. Between $13 \%$ and $16 \%$ of all institutional deliveries from 2001 to 2010 occurred under the CY PPP $[12,13]$. Since the implementation of the CY scheme, studies have shown it has been successful in increasing the geographic availability of free intra-partum care for eligible women [14]. However, considering that annually 570,625 births occur among eligible women and only 155,721 of these occur under CY, approximately $73 \%$ of poor and tribal women did not utilize the free delivery service. This indicates there is scope for improvement in utilization of the scheme. Most of the previous research on CY has been from the health facility' perspective [12, 15-17]. However, utilization among eligible women in the community needs to be studied in order to understand reasons for poor uptake of the CY program. This has not been reported in a previous community-based study on the CY published recently [7] or in older reports [9]. Though CY helped in saving $\$ 75$ per delivery among those who utilized CY when compared to eligible women who delivered in a non-accredited private facility and paid fully out-of-pocket, out-of-pocket expenditures (OOPE) were still incurred among those who benefited from the program $[9,18]$.

This study attempts to document the factors associated with non-utilization of the CY program by eligible women who had recently given birth. Specific objectives were to i) determine the proportion of eligible women who utilized CY program; and ascertain among those who did not utilize the program the proportion delivering at home, Government facility, accredited private facility and non-accredited private facility, ii) determine the association between socio-demographic and pregnancyrelated characteristics with non-utilization of CY program, iii) describe self-reported reasons for not availing CY benefit despite delivering at an accredited private facility, and iv) determine facility-wise OOPE with a focus on comparison of OOPE between those who delivered at Government facility and utilized CY after adjusting for type of delivery.

\section{Methods}

\section{Study design}

This was a community-based cross sectional study. This study was part of a large scale community-based Maternal Health India (MATIND) project aimed to study the CY program in the state of Gujarat.

\section{Study setting \\ Gujarat state}

Gujarat state (population 60.4 million) is comprised of 26 districts (currently 33 districts), the average population of a district is two million. Districts are further divided into 10-20 blocks (sub-districts) of approximately 100,000 to 200,000 people. These districts have varying human development indices and different population compositions $[19,20]$. The population is divided into socio-economic sub groups by caste. Government of India uses the terms 'Schedule Caste,' 'Tribe' to denote these traditionally marginalized population subgroups. In addition the term 'below poverty line' (BPL) is also used to denote economically disadvantaged families. These two groups are recipients of official documentation from the government confirming tribal or BPL status. This documentation is used to avail special benefits under a broad program of positive affirmative action. 
We use the term 'socially disadvantaged groups' throughout the article which includes both schedule tribes (ST) and BPL.

\section{Study sites}

Three heterogeneous districts from the western, central and eastern belts of the Gujarat state, Sabarkantha, Surendranagar and Dahod, (Fig. 1) were selected for the study. 'The three districts were purposively selected, one each from high, medium and low human development index and different population compositions, i.e., varying proportions of tribes and populations living below the poverty line from diverse geographic areas. The detail indicators of these sampled districts are shown in Appendix Table.

\section{Study population and sampling}

The study population included eligible women in the study districts who delivered between January and July 2013. As CY providers were not evenly distributed geographically throughout the district, blocks in each district were selected to represent areas where there were no, low (one or two providers) or high number (more than two per block) of CY providers. In brief, in each of the 3 districts, 3-5 blocks were selected purposively. A list of all the villages in these blocks was compiled using the criteria: village population more than 1,000 and less than 2,500, greater than $40 \%$ BPL population and scattered all over the block. From the list, 142 villages were selected randomly to cover approximately 300,000 populations.

\section{Data collection and variables}

Data collection was done between July and November 2014. Trained researcher visited the homes of eligible women who had given birth between January 2013 and July 2013 and administered a questionnaire. Local female village health volunteer helped researchers identify respondents. On an average, the administration of the questionnaire took $15 \mathrm{~min}$.

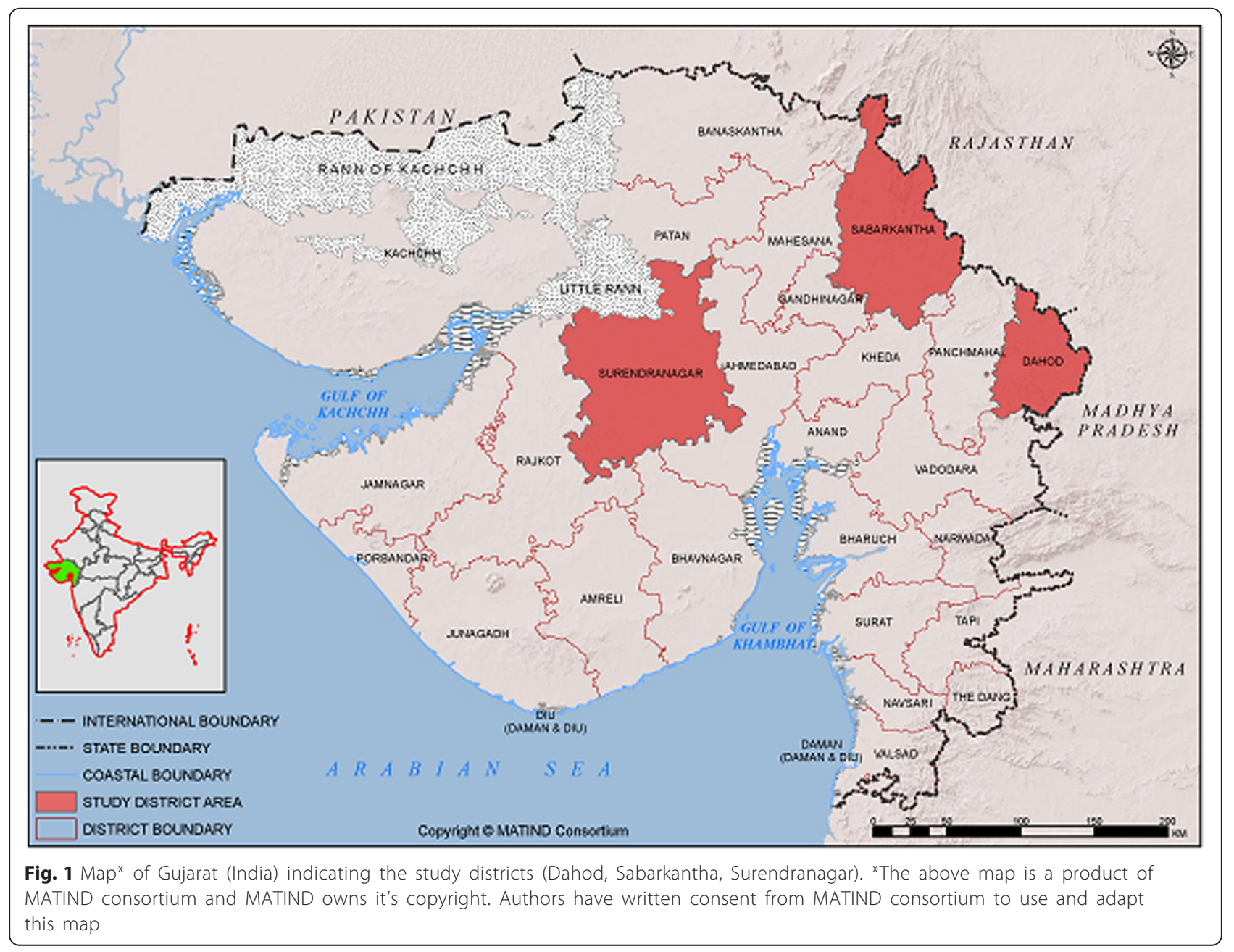




\section{Dependent variables}

For objective ii, the dependent variable was non-utilization of CY (Fig. 2) and for objective iv, it was OOPE. The operational definitions used were:

i. Government facility delivery: women who delivered at any government facility, which provided free institutional delivery care.

ii. CY utilization among eligible women was defined as delivery in an accredited facility and receipt of either completely free or partially subsidized intra-partum care under the $\mathrm{CY}$.

iii. $C Y$ non-utilization comprised three different groups of women: (i) those who did not receive any benefit but delivered in a CY accredited facility, (ii) those who delivered in a non-accredited private facility or (iii) those who gave birth at home.

iv. OOPE: The total expense made by the woman/or her family including direct costs i.e. delivery care and indirect costs related to the birth i.e. treatment related other than delivery, transportation, food, and items purchased for the baby were expressed in USD (corrected for June 2015) after accounting for

discounting for inflation between 2013 and 2015.

\section{Independent variables}

Socio-demographic characteristic collected were age, education categorized based on the number of years studied, earning status, religion, caste, and the standard of living index (SLI). The questionnaire included questions on household assets, living and sanitation conditions etc. from the National Family Health Survey and were used to create the SLI [21]. A score was calculated for each women based on pre-determined weights for 27 different components. The scores were subsequently divided into five quintiles $\left(1^{\text {st }}\right.$ being the poorest and the $5^{\text {th }}$ the wealthiest women in the survey) [22]. Pregnancy and childbirth associate variables collected were antenatal checkups defined as having a visit in the first trimester and at least three total antenatal visits during the pregnancy, self-reported pregnancy complications i.e. anemia, urinary tract infection, hypertension, parity, birth attendant, and type of delivery (i.e. vaginal or cesarean section).

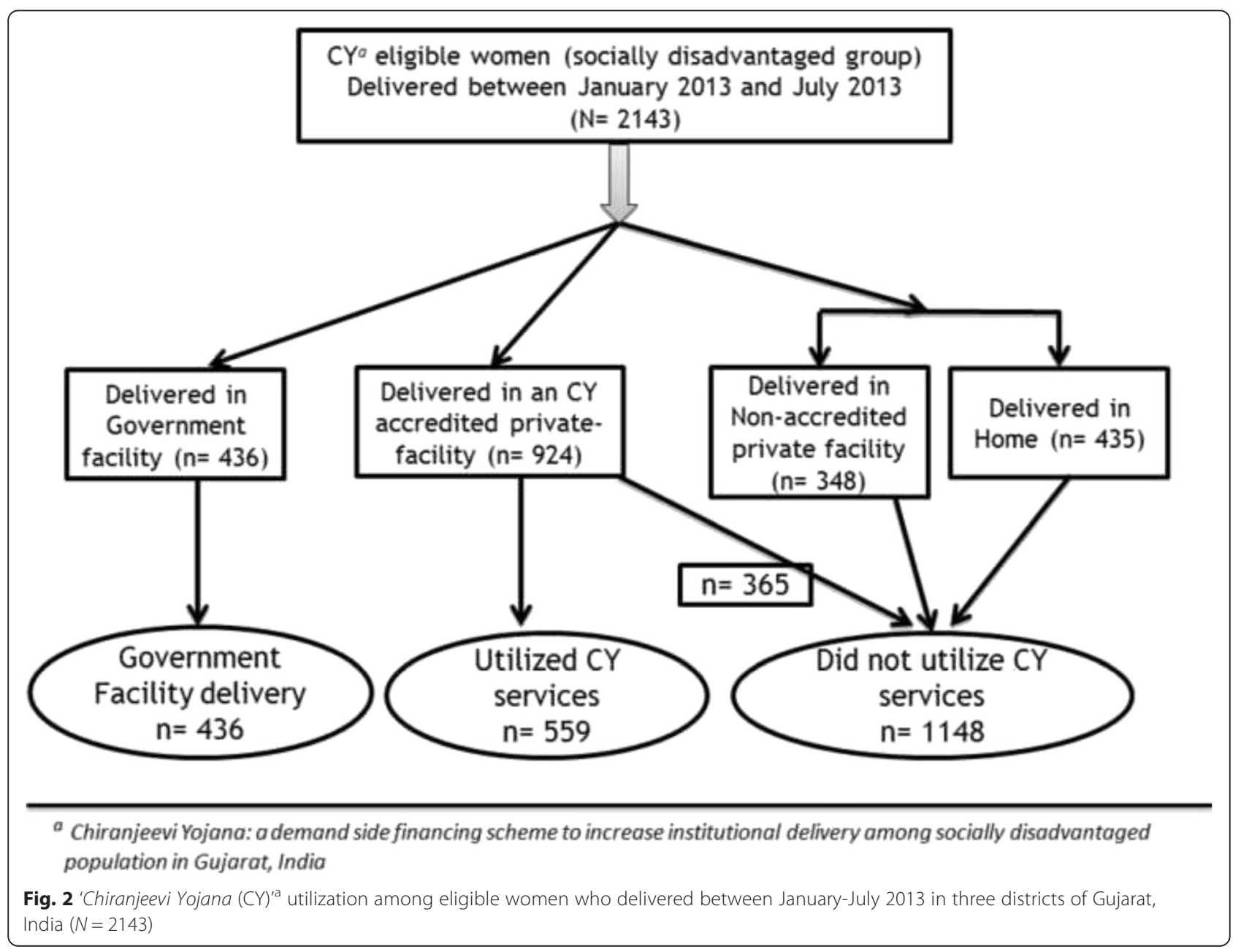




\section{Data entry and analysis}

Data from the interview scheduled were double-entered and validated in an online data management system i.e. Research Electronic Data Capture (REDCap) [23]. The database for this study was imported to EpiData analysis software v2.2.2.183 (EpiData Association, Odense, Denmark) for descriptive analysis and bivariate inferential analysis. STATA (version 12.1) was used for multivariable inferential analysis.

For objective i and iii, descriptive statistics (frequencies, proportions, median, and interquartile range) were used to summarize categorical and continuous variables. All independent variables and OOPE were described for the following categories: CY non-utilization, CY utilization and those delivering in Government facility.

Those who delivered in a Government facility were excluded from the analysis to study predictors associated with CY non-utilization. Variables with univariate $p$-value $<0.2$ were included in the binomial logistic regression model (forward LR method). Adjusted odds ratio (aOR) was used to describe the association between $\mathrm{CY}$ non-utilization (outcome) and socio-demographic/pregnancy related characteristics (exposure). Prior to building the model, we checked for collinearity between predictor variables and if collinear, then the variables were excluded from the model.

Among women who should have received free delivery services under either the $\mathrm{CY}$ or in government facilities, we compared out-of-pocket expenditures. Beta coefficient (linear regression-forward method) was used to summarize the association between $\log _{10}$ OOPE (outcome) and CY utilization (exposure) after adjusting for type of delivery and other variables. $\log _{10}$ transformation was performed on the outcome variable (OOPE) as it was not normally distributed. $95 \%$ confidence interval (CI) was used to infer the above summary statistics.

\section{Results}

\section{Study sample characteristics and CY utilization}

As shown in Fig. 2, among the 2,143 eligible women, 559 (26\%) were CY beneficiaries. A further 365 (17\%) gave birth at $\mathrm{CY}$ accredited facilities but did not benefit from the program, 436 (20\%) delivered at Government facilities, $348(17 \%)$ at non-accredited CY private facilities and $435(20 \%)$ at home. The socio demographic characteristics of the eligible women are shown in Table 1. There was a higher proportion of mothers with no formal education among those giving birth at home (62\%) and delivering in Government facilities (53\%), compared to those who utilized CY (32\%), delivered in CY accredited but did not utilize CY (40 \%) and delivered in non-accredited private
(31 \%) facilities. As shown, the women in the survey were mostly multiparous with a majority having at least one ANC check-up. A higher proportion of primiparous mothers utilized CY (44\%) when compared to primiparous women who delivered at home (25\%). Similarly as seen in Table 2, a higher proportion of women with no ANC check-ups were found among those who gave birth at home (20\%) compared those who utilized CY (9\%). There was a lower proportion of intra-natal (INC) complication (3\%), ANC complication (4\%) and C-sections (3\%) among mothers who utilized $\mathrm{CY}$ when compared to deliveries that occurred in $\mathrm{CY}$ accredited but did not utilize $\mathrm{CY}$ and non $\mathrm{CY}$ accredited facilities.

\section{Determinants of $\mathrm{CY}$ non-utilization}

Eligible women who belonged to scheduled tribe or BPL $[\mathrm{aOR}=3.1,95 \% \mathrm{CI}: 2.4-3.8]$ or and having no formal education $[\mathrm{OR}=1.6,95 \% \mathrm{CI}: 1.1,2.2]$ had higher odds of not utilizing $\mathrm{CY}$ scheme. Women who delivered by $\mathrm{C}$ section had twice the odds $[\mathrm{aOR}=2.1,95 \% \mathrm{CI}: 1.2,3.8]$ of not utilizing CY. Standard of living, parity, ANC visits and ANC complications had high collinearity with delivery type and were therefore not included in the model (Table 3).

\section{Reasons for CY non-utilization in a CY facility}

Non-utilization of CY among eligible mothers delivering at CY accredited facility was $40 \%$ (365/924). The reasons included: (i) no documentation i.e. what is essential in order to get the benefit at the time of delivery ( $n=262,72 \%$ ), (ii) mother belonged to a different district $(n=76,21 \%)$, and (iii) lack of CY program awareness $(n=36,10 \%)$.

\section{CY utilization and OOPE}

Median OOPE stratified by place of delivery is described in Table 4. Overall, the median OOPE those who did not utilize CY at accredited and non-accredited private facility was $\$ 75$ and $\$ 90$, respectively. Median OOPE among those who utilized $\mathrm{CY}$ and those delivering at a Government facility was $\$ 12$ and $\$ 3$, respectively. Median OOPE among home delivery mothers was found to be $\$ 5$. CY utilization resulted in significantly higher OOPE compared to women who delivered in a Government facility after adjusting for type of delivery (Table 5).

\section{Discussion}

This study highlighted that of eligible mothers, after excluding government delivery; more than two-thirds did not utilize CY program benefits. Although $20 \%$ of the women delivered in public sector facilities, there was scope for shifting those from delivering at home or at a 
Table 1 Socio-demographic characteristics and 'Chiranjeevi Yojana $(C Y)^{\text {'a }}$ utilization among eligible women ${ }^{b}$ in three districts ${ }^{c}$ of Gujarat, India (Jan-July 2013) (N=2143)

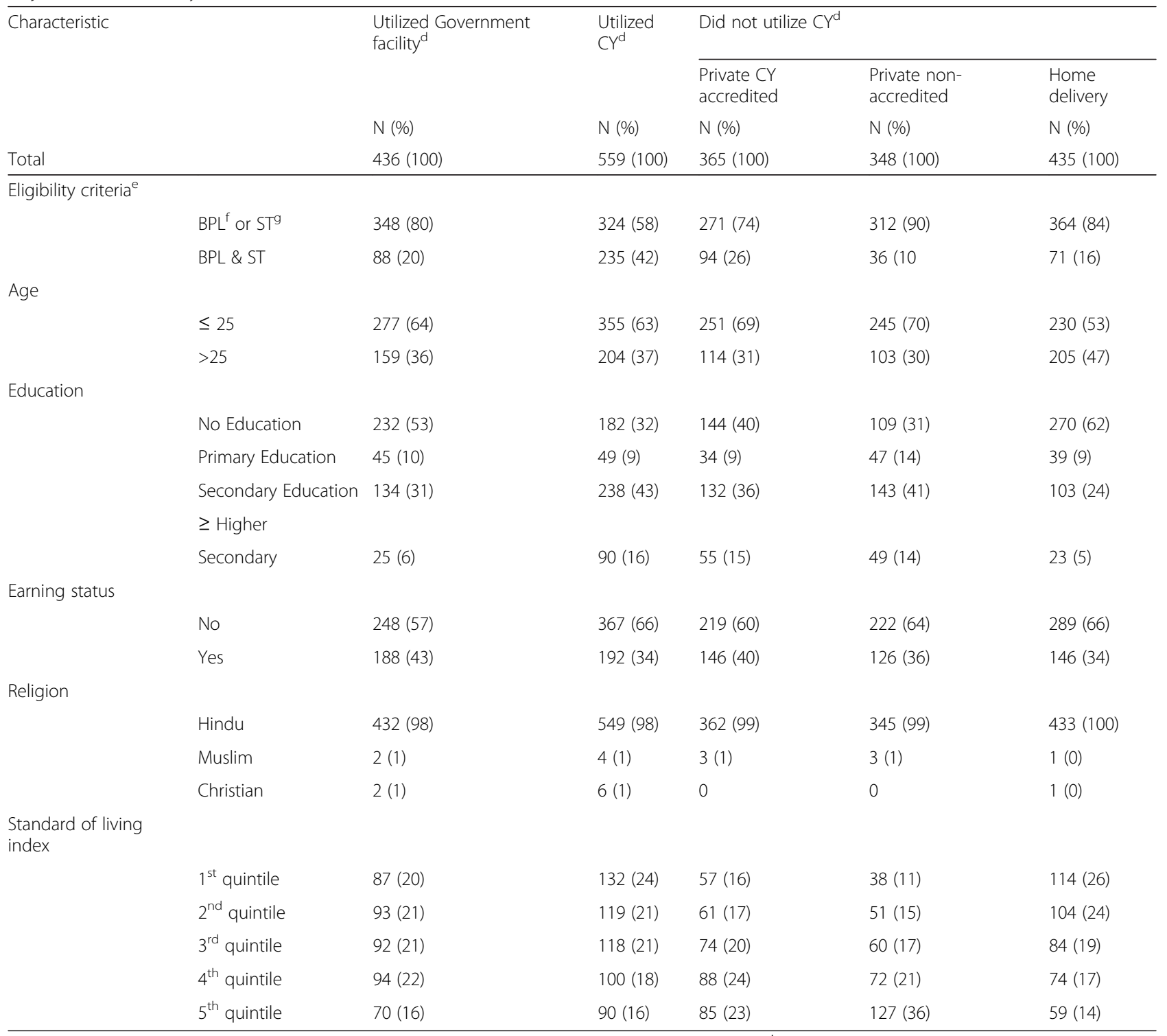

${ }^{a}$ demand side financing scheme to increase institutional delivery among socially disadvantaged population; ${ }^{\text {b }}$ women belonging to socially disadvantaged population; 'Dahod, Sabarkantha, Surendranagar; ${ }^{\mathrm{d}}$ column percentage; ${ }^{\mathrm{e}}$ socially disadvantaged groups which includes both schedule tribes and below poverty

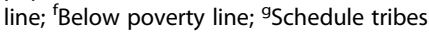

private facility (including an accredited facility where women faced barriers) into CY. Though the nonutilization group is heterogeneous (women who gave birth at home, women who delivered in non-accredited CY private facilities and women who delivered in a $\mathrm{CY}$ accredited facility but did not receive the benefit), we need different strategies for different group. Interestingly, about two-fifths of eligible women who delivered at a CY facility did not receive the benefit of a free delivery. In addition, those who utilized CY incurred higher out-of-pocket expenses when compared to women who delivered in a Government facility.

\section{CY non-utilization \& child birth at home}

First and foremost is the reason for non-utilization and most important group belong to women who gave birth at home. Though home deliveries were found only in $8 \%$ of all deliveries in the state [24], this study found that about $20 \%$ of these socially disadvantaged mothers gave child birth at home; this indicates that home based child birth is more concentrated in these socially disadvantaged group. These mothers were poor, young, having no formal education, multiparous and had no $/<3$ ANC visits, which is similar in line of previous predictor-based study on home delivery [25]. This group 
Table 2 Pregnancy related characteristics and 'Chiranjeevi Yojana $(C Y)^{\prime a}$ utilization among eligible women ${ }^{b}$ in three districts ${ }^{c}$ of Gujarat, India (Jan-July 2013) (N=2143)

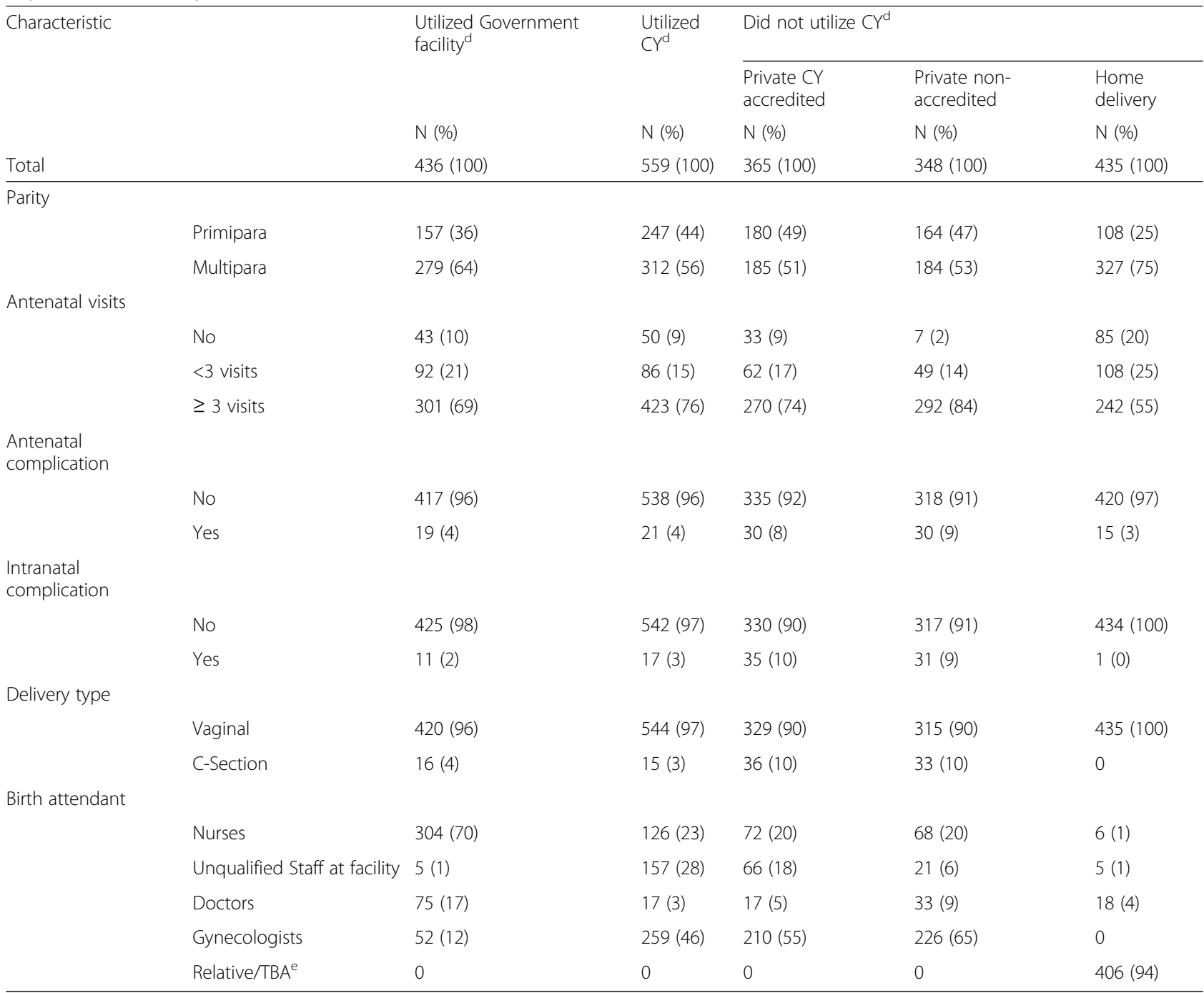

${ }^{a}$ demand side financing scheme to increase institutional delivery among socially disadvantaged population; ${ }^{\mathrm{b}}$ women belonging to socially disadvantaged population; ' Dahod, Sabarkantha, Surendranagar; ${ }^{d}$ column percentage, ${ }^{\text {eTraditional Birth Attendant }}$

may be targeted early on in the antenatal period with awareness generation programs for non-literate mothers about the scheme and the documentation requirement [26]. Specific efforts are needed to help these mothers obtain the required documentation which could be facilitated and monitored by a community health worker (the Accredited Social Health Activists (ASHA)). The same awareness programs and efforts by ASHA should target home deliveries.

\section{CY non-utilization \& child birth at non-accredited private facilities}

The second group targets women who delivered in nonaccredited $\mathrm{CY}$ private facilities. Eligible women belonging to higher quintiles of the standard of living index (relatively better off among vulnerable women) were also more likely to not utilize the scheme. Women with higher education and women who had adequate ANC visits gave birth in non-accredited $\mathrm{CY}$ private facilities: relatively well-off women among the eligible population may more choice for place of delivery and they choose to have child birth in a private facility.

\section{CY non-utilization \& child birth at $\mathrm{CY}$ accredited private facilities}

Despite reaching to a $\mathrm{CY}$ facility there are group of women (about $40 \%$ ) who become did not utilize CY. In our previous facility based study [18], about two-third of eligible women who reached a CY facility did not utilize $\mathrm{CY}$, which is higher than this report. Similar to previous study [18] most common reason given for nonutilization by the women was lack of proper 


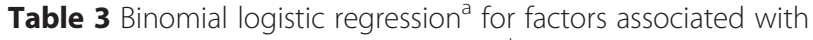
non-utilization of 'Chiranjeevi Yojana (CY)'b among eligible women ${ }^{c}$ in three districts ${ }^{d}$ of Gujarat, India (Jan-July 2013) $(N=1707)^{e}$

\begin{tabular}{|c|c|c|c|}
\hline Variable & & $\begin{array}{l}\text { Crude OR } \\
(95 \% \mathrm{Cl})\end{array}$ & $\begin{array}{l}\text { Adjusted OR } \\
(95 \% \mathrm{Cl})^{\mathrm{g}}\end{array}$ \\
\hline \multicolumn{4}{|c|}{$\begin{array}{l}\text { Socio-demographic } \\
\text { characteristics }\end{array}$} \\
\hline \multicolumn{4}{|c|}{ Eligibility criteria ${ }^{h}$} \\
\hline & BPL or ST & $3.4(2.7,4.3)$ & $3.1(2.4,3.8)$ \\
\hline & $\mathrm{BPL}$ and ST & Reference & Reference \\
\hline \multicolumn{4}{|l|}{ Age } \\
\hline & $18-25$ & Reference & Reference \\
\hline & $>25$ & $1.0(0.8,1.2)$ & $0.98(0.8,1.2)$ \\
\hline \multicolumn{4}{|c|}{ Education } \\
\hline & No Education & $2.0(1.5,2.8)$ & $1.6(1.1,2.2)$ \\
\hline & Pri. Education & $1.7(1,1,2.7)$ & $1.2(0.8,1.9)$ \\
\hline & Sec. Education & $1.1(0.8,1.5)$ & $1.0(0.7,1.4)$ \\
\hline & $\geq$ Higher Sec. & Reference & Reference \\
\hline \multicolumn{4}{|c|}{ Standard of living index } \\
\hline & $1^{\text {st }}$ quintile & Reference & - \\
\hline & $2^{\text {nd }}$ quintile & $1.2(0.8,1.6)$ & - \\
\hline & $3^{\text {rd }}$ quintile & $1.2(0.9,1.6)$ & - \\
\hline & $4^{\text {th }}$ quintile & $1.5(1.1,2.0)$ & - \\
\hline & $5^{\text {th }}$ quintile & $1.5(1.1,2.0)$ & - \\
\hline \multicolumn{4}{|c|}{$\begin{array}{l}\text { Pregnancy related } \\
\text { characteristics }\end{array}$} \\
\hline \multicolumn{4}{|l|}{ Parity } \\
\hline & Primipara & Reference & - \\
\hline & Multipara & $1.2(0.99,1.5)$ & - \\
\hline \multicolumn{4}{|c|}{ Antenatal visits } \\
\hline & No & $1.3(0.9,1.9)$ & - \\
\hline & $<3$ visits & $1.3(1.02,1.8)$ & - \\
\hline & $\geq 3$ visits & Reference & - \\
\hline \multicolumn{4}{|c|}{ Antenatal complication } \\
\hline & No & Reference & - \\
\hline & Yes & $1.8(1.1,2.9)$ & - \\
\hline
\end{tabular}

Delivery type

\begin{tabular}{lll} 
Vaginal & Reference & Reference \\
C-Section & $2.3(1.3,4.1)$ & $\mathbf{2 . 1}(\mathbf{1 . 2}, \mathbf{3 . 8})$ \\
\hline
\end{tabular}

${ }^{\mathrm{a} F o r w a r d ~ L R ~ m e t h o d ~ w i t h ~ C Y ~ n o n-u t i l i z a t i o n ~ a s ~ o u t c o m e ; ~}{ }^{\text {b demand side financing }}$ scheme to increase institutional delivery among socially disadvantaged population; 'women belonging to socially disadvantaged population; ${ }^{\mathrm{d} D a h o d, ~ S a b a r k a n t h a, ~}$ Surendranagar; ${ }^{\text {eWomen }}$ who delivered in Government facility were excluded; fvariables with bivariate $p<0.2$ shown in table, ${ }^{9}$ Standard of living, parity, ANC visits and ANC complications had high collinearity with delivery type and were therefore not included in the model, ${ }^{\mathrm{h}}$ sociallydisadvantaged groups which includes both schedule tribes and below poverty line

Model chi square: 134.6, df: 12, $p<0.001$; Pseudo Rsquare: 0.06 ; Hosmer and Lemeshow Chi square: 8.15 , df: $8, p=0.419$

OR mentioned as bold are significant values in the model

documentation and being unaware of the CY scheme itself or of paperwork necessary to become a beneficiary. This was also highlighted by Bhimani et al.; most of the participants who were actually the beneficiaries of the scheme were unaware of 'Chiranjeevi Scheme' and authors recommended that Information Education \& Communication (IEC) activities with emphasis on Government programs focusing on maternal and child health should be strengthened [27]. Women who had a $\mathrm{C}$-section delivery were more likely to not utilize the program in our study. Though we did not explore why this was the case, a previous study in our setting suggested that private accredited facilities would sometimes shift potential cesarean section (C-Section) births out of the $\mathrm{CY}$ program because of the bundled financial reimbursement package which did not specifically incentivize C-Section [16].

\section{CY utilization \& out-of-pocket expenditures}

Interestingly, in comparison, women who gave birth at home paid some out of pocket money (\$5) for services rendered by the birth attendant, which was even higher than from giving birth at government facilities (\$3.3). Similar to previous studies $[9,18]$ this study found that women receiving the $\mathrm{CY}$ benefit had some delivery related expenditure $(\$ 11.70)$ and it was significantly less than those who did not utilize CY scheme and delivered in a private facility $(\$ 75-\$ 90)$. Sidney et al. [18] also highlighted that; CY beneficiaries experienced a substantially subsidized childbirth compared to women who delivered in non-accredited private facilities, but often not completely free childbirth services as envisaged by the program. Our study found that OOPE among $\mathrm{CY}$ utilization was significantly higher than for those giving birth at a Government facility. OOPE among mothers who utilized $\mathrm{CY}$ are expected to be either zero or at best similar to OOPE in a Government facility. While women, who utilized the CY PPP, did not incur any expenses towards services in the facility, they still had other expenditures particularly travel and therefore overall paid more than women who delivered in the public sector. Although this was not explored, one could postulate that OOPE despite CY utilization could be a factor resulting in non-utilization in next delivery. A study by Vora et al. found that women travelled longer distance to avail benefits from $\mathrm{CY}$ services [14]. This distance involved is likely to contribute to expenses related to transportation which CY beneficiaries incurred, but not women who give birth in closer government facilities.

\section{Methodological consideration}

The main strength of this study is that this is a large primary community based survey that reported for the first time on the uptake of the CY program based on empirical data. One of the limitations of this study was that we did not explore the reasons behind child birth at 
Table 4 Median delivery related out of pocket expenditure a and 'Chiranjeevi Yojana $(C Y)^{\text {bb }}$ utilization among eligible women ${ }^{\mathrm{c}}$ who delivered between Jan-Jul 2013 in three districts ${ }^{d}$ of Gujarat, India (N=2143)

\begin{tabular}{|c|c|c|c|c|c|}
\hline \multirow[t]{2}{*}{ Characteristic } & \multirow[t]{2}{*}{ Utilized Government facility } & \multirow[t]{2}{*}{ Utilized CY } & \multicolumn{3}{|l|}{ Did not utilize $\mathrm{CY}$} \\
\hline & & & Private CY accredited & Private non-accredited & Home delivery \\
\hline Delivery expenses & $0(0-0)$ & $0(0-8.3)$ & $58.3(41.7-83.3)$ & $66.7(50-100)$ & $3.3(0-9.6)$ \\
\hline Other treatment expenses & $0(0-0)$ & $0(0-0)$ & $0(0-0)$ & $0(0-2.1)$ & $0(0-0)$ \\
\hline Food expense & $0(0-0)$ & $0(0-0)$ & $0(0-0)$ & $0(0-3.3)$ & $0(0-0)$ \\
\hline Transportation expense & $0(0-5)$ & $6.7(1.7-8.3)$ & $8.3(3.3-13.3)$ & $6.7(3.3-11.7)$ & $0(0-0)$ \\
\hline Baby expenses & $0(0-0)$ & $0(0-0)$ & $0(0-0)$ & $0(0-1.7)$ & $0(0-0)$ \\
\hline Total [median, (IQR)] & $3.3(0-10)$ & $11.7(5-23.3)$ & $75(53.3-103.3)$ & $90(60-131.7)$ & $5(0-10)$ \\
\hline
\end{tabular}

${ }^{a}$ USD (corrected for June 2015) after accounting for discounting, b demand side financing scheme 'Chiranjeevi Yojana (CY)' to increase institutional delivery among socially disadvantaged population; ' ${ }^{2}$ women belonging to socially disadvantaged population; ${ }^{\mathrm{d} D a h o d, ~ S a b a r k a n t h a, ~ S u r e n d r a n a g a r}$

home or in government or non-accredited private facilities. CY non-utilization was a heterogeneous group; this might have affected the estimates in our analysis. In addition, assessment of eligibility for $\mathrm{CY}$ scheme by the investigators was done at the time of survey. We believe that the study finding are representative, acknowledging the fact that our sampling method not being random might limit the extrapolation of the study finding to the population of $\mathrm{CY}$ eligible mothers.

\section{Policy implications}

First, ensuring that a woman has appropriate eligibility documentation at the time of delivery is important to

Table 5 Factors associated with out-of pocket expenditure among women eligible ${ }^{\mathrm{b}}$ for $\mathrm{CY}^{\mathrm{c}}$ who delivered between Jan-Jul 2013 in three districts ${ }^{d}$ of Gujarat, India ( $\left.N=995\right)$

\begin{tabular}{lllll}
\hline Variable $^{\text {e }}$ & & $\beta$ coefficient & $0.95 \mathrm{Cl}$ & $p$-value \\
\hline Place of delivery $^{f}$ & CY utilizer & 0.21 & $0.15,0.27$ & $<0.001$ \\
& $\begin{array}{l}\text { Government } \\
\text { facility }\end{array}$ & Reference & & \\
Type of delivery & C-section & 0.80 & $0.66,0.95$ & \\
& Vaginal & Reference & & $<0.001$ \\
Eligibility criteria ${ }^{9}$ & BPL or ST & 0.07 & $0.01,0.13$ & \\
& BPL and ST & Reference & & 0.02 \\
& & 0.67 & {$[0.47,0.86]$} & $<0.001$ \\
\hline
\end{tabular}

${ }^{a}$ USD (corrected for June 2015) after accounting for discounting followed by log transformation; ${ }^{b}$ women belonging to socially disadvantaged population; 'demand side financing scheme 'Chiranjeevi Yojana (CY)' to increase institutional delivery among socially disadvantaged population; ${ }^{d}$ Dahod, Sabarkantha, Surendranagar; ${ }^{e}$ Variables added to linear regression model (forward method) were place of delivery, delivery type, eligibility criteria, age group and education status: latter two were not included by the model; ${ }^{f}$ Standard of living, parity, ANC visits and ANC complications had high collinearity with delivery type and were therefore not included in the model; ${ }^{9}$ socially disadvantaged groups which includes both schedule tribes and below poverty line Model F stat: $54.5 ; p<0.001$ gain access to the $\mathrm{CY}$ program. A convergence approach can be considered where all accredited health facilities have access to the available list of eligible women/families in their district. This will allow more women to become beneficiaries automatically if they are in the list at each facility rather than placing the onus of providing appropriate documentation on the women/family. There are two groups that need focus in terms of increasing uptake of the program, one are those who delivered outside a CY facility (women who delivered at home received no care and women who delivered in private facilities, both of whom had OOPE) and those who managed to get to a CY facility but didn't get the become CY beneficiaries. Community awareness needs to be strengthened to reach both these groups to improve uptake of the CY PPP.

Second, more effective monitoring of private partners is necessary to ensure that there is no 'creamskimming' of cases so that women with complications are not excluded from CY. Third, women who utilized CY still face some financial access barriers in the form of indirect costs, particularly transport which could be a deterrent to utilization by poor women. Further research is required to determine whether OOPE in utilization in current delivery results in non-utilization in the next birth.

\section{Conclusion}

Our study showed that almost a decade of implementation, the uptake of the Chiranjeevi Yojana among eligible women is still low. There is a need for community level awareness programs to increase participation among eligible women. The out-of-pocket expenses to cover indirect costs associated with CY utilization among socially disadvantaged group needs to be looked into. There is also a need to put in place monitoring mechanisms to ensure women with complications are not excluded from the CY program. 


\section{Appendix}

Table 6 Demographic characteristics of MATIND ${ }^{a}$ study districts of Gujarat, India

\begin{tabular}{llll}
\hline Indicators $^{\text {b }}$ & Dahod & Sabarkantha & Surendranagar \\
\hline Populations (in millions) & 2.1 & 2.4 & 1.7 \\
Rural population (\%) & 91 & 85 & 72 \\
BPL $^{c}$ population (\%) & 72 & 33 & 47 \\
ST $^{d}$ population (\%) & 73 & 22 & 01 \\
Literacy rate (\%) $_{\text {Total private providers (number) }}$ & 59 & 65 & 62 \\
CYe $^{e}$-accredited private providers & 8 & 83 & 38 \\
(number) & 23 & 21
\end{tabular}

(number)

${ }^{a}$ Maternal Health India Project, ${ }^{b}$ Size, Growth Rate and distribution of Population-Provisional Population Totals: Census of India-2011 ${ }^{\mathrm{C} P o p u l a t i o n}$ living in Below Poverty Line; ${ }^{\mathrm{d}}$ Population belongs to Social Tribe; ${ }^{\mathrm{e}}$ demand side financing scheme 'Chiranjeevi Yojana (CY)

\section{Abbreviations}

ANC, antenatal care; aOR, adjusted odds ratio; ASHA, accredited social health activists; BPL, below poverty line; Cl, confidence interval; C-section, cesarean section; CY, Chiranjeevi Yojana; DSF, demand-side financial incentives; IEC, information education \& communication; INR, Indian Rupees; MATIND, maternal health India; MDG, millennium development goals; OOPE, out-of-pocket expenditures; PPP, public-private-partnership; REDCap, research electronic data capture; SDG, sustainable development goal; SLI, standard of living index; ST, schedule tribe

\section{Acknowledgement}

We acknowledge project field staff and partners of the EU FP7 supported MATIND project under which this work was undertaken. The MATIND project also acknowledges the Department of Health, Government of Gujarat for support. The first author received support for analysis and writing through the Structured Operational Research and Training Initiative (SORT IT), a global partnership led by the Special Programme for Research and Training in Tropical Diseases at the World Health Organization (WHO/TDR). The model is based on a course developed jointly by the International Union Against Tuberculosis and Lung Disease (The Union) and Medécins sans Frontières. The specific SORT IT programme which resulted in this publication was jointly developed and implemented by: The Union South-East Asia Regional Office, New Delhi, India; the Centre for Operational Research, The Union, Paris, France; the Operational Research Unit (LUXOR), Médecins Sans Frontières, Brussels Operational Center, Luxembourg; Department of Community Medicine, Sri Manakula Vinayagar Medical College and Hospital Puducherry, India; and the Department of Preventive and Social Medicine, Jawaharlal Institute of Postgraduate Medical Education \& Research, Puducherry, India.

\section{Funding}

The MATIND project leading to these results been funded by European Community's Seventh Framework Programme under grant agreement no. 261304. The SORT IT was funded by the Department for International Development (DFID), UK. The funders did not have role in study design, data collection and analysis, decision to publish, or preparation of the manuscript.

\section{Availability of data and materials}

Data are available from the Indian Institute of Public Health Gandhinagar Institutional Data Access/Ethics Committee for researchers who meet the criteria for access to confidential data. The contact person for obtaining data is Prof Dileep Mavalankar, Director, Indian Institute of Public Health Gandhinagar. Email: dmavalankar@iiphg.org.

\section{Authors' contributions}

Conception/design of the protocol - SY, KSV, KSA HDS, PI, DVM, ADC Acquisition of data - SY, KSV, DVM; data analysis/interpretation - SY, KSV,
HDS, KSA, PI, DVM, NBD, ADC; Drafting the first draft of the paper - SY, HDS, KSA; Critically reviewing the paper and approval of final draft - all authors.

\section{Competing interests}

The authors declare that they have no competing interests.

\section{Consent for publication}

Not applicable.

Ethical approval and consent to participate

Written informed consent was obtained from all the women who participated in the MATIND community based survey and the consent process was approved by the ethics committee. Ethics approval was obtained from the Institutional Ethics Committee of the Indian Institute of Public Health, Gandhinagar India and Ethics Advisory Group of the International Union Against Tuberculosis and Lung Disease (The Union), Paris, France.

\section{Author details}

Indian Institute of Public Health-Gandhinagar, Sardar Patel Institute Campus, Drive-in-Road, Ahmedabad, Gujarat 380054, India. ${ }^{2}$ International Union Against Tuberculosis and Lung Disease (The Union), South East Asia Office, New Delhi, India. ${ }^{3}$ Karolinska Institutet, Solna, Sweden. ${ }^{4}$ Médecins Sans Frontières (MSF)/Doctors Without Borders, Mumbai, India. ${ }^{5}$ Department of Health \& Family Welfare, Government of Gujarat, Gandhinagar, India.

Received: 20 April 2016 Accepted: 5 July 2016

Published online: 15 July 2016

\section{References}

1. Lagarde M, Haines A, Palmer N. Conditional cash transfers for improving uptake of health interventions in low- and middle-income countries: a systematic review. JAMA. 2007;298:1900-10.

2. Jehan K, Sidney K, Smith H, de Costa A. Improving access to maternity services: an overview of cash transfer and voucher schemes in South Asia. Reprod Health Matters. 2012;20:142-54.

3. Gopalan SS, Das A, Mutasa R. What makes Health Demand-Side Financing Schemes Work in Low-and Middle-Income Countries? A Realist Review. J Public Health Res. 2014;3:304

4. van Teijlingen E, Hundley V, Matthews Z, Lewis G, Graham WJ, Campbell J, Ten Hoope-Bender P, Sheppard ZA, Hulton L. Millennium development goals: all good things must come to an end, so what next? Midwifery. 2014;30:1-2.

5. Lagarde M, Haines A, Palmer N. The Impact of Conditional Cash Transfers on Health Outcomes and Use of Health Services in Low and Middle Income Countries (Review): The Cochrane Library 2009, Issue 4. 2009.

6. Mavalankar DV, Vora KS, Ramani KV, Raman P, Sharma B, Upadhyaya M. Maternal health in Gujarat, India: a case study. J Health Popul Nutr. 2009;27:235-48

7. Mohanan M, Bauhoff S, La Forgia G, Babiarz KS, Singh K, Miller G. Effect of Chiranjeevi Yojana on institutional deliveries and neonatal and maternal outcomes in Gujarat, India: a difference-in-differences analysis. Bull World Health Organ. 2014;92:187-94.

8. Chiranjeevi Yojana. Department of Health \& Family Welfare, Governement of Gujarat, India. Available from: https://gujhealth.gujarat. gov.in/chirnajivi-yojana-gujarat.htm. Accessed May 2015.

9. Bhat R, Mavalankar DV, Singh PV, Singh N. Maternal healthcare financing: Gujarat's Chiranjeevi Scheme and its beneficiaries. J Health Popul Nutr. 2009:27:249-58

10. Graham WJ, Bell JS, Bullough CHW. Can skilled attendance at delivery reduce maternal mortality in developing countries? In: De Brouwere $\mathrm{WL}$, Van Lerberghe W; ed. Safe motherhood strategies: a review of the evidence Antwerp: ITG Press; 2001;97-130.

11. Saxena D, Nakkeeran S, Vangani R, Mavalankar D. Trends in institutional deliveries among disadvantaged groups and the impact of intervention in Gujarat: evidence from secondary data analysis. Lancet. 2013;381:S129.

12. De Costa A, Vora KS, Ryan K, Sankara Raman P, Santacatterina M, Mavalankar D. The State-Led Large Scale Public Private Partnership "Chiranjeevi Program" to Increase Access to Institutional Delivery among Poor Women in Gujarat, India: How Has It Done? What Can We Learn? PLoS One. 2014;9, e95704. 
13. Government of Gujarat G. District Level Rapid Household Survey (DLRHS) 2011. 2012.

14. Vora KS, Yasobant S, Patel A, Upadhyay A, Mavalankar DV. Has Chiranjeevi Yojana changed the geographic availability of free comprehensive emergency obstetric care services in Gujarat, India? Glob Health Action. 2015;8:28977.

15. Mavalankar D, Singh A, Patel SR, Desai A, Singh PV. Saving mothers and newborns through an innovative partnership with private sector obstetricians: Chiranjeevi scheme of Gujarat, India. Int J Gynaecol Obstet. 2009;107:271-6.

16. Ganguly P, Jehan K, de Costa A, Mavalankar D, Smith H. Considerations of private sector obstetricians on participation in the state led "Chiranjeevi Yojana" scheme to promote institutional delivery in Gujarat, India: a qualitative study. BMC Pregnancy Childbirth. 2014;14:352.

17. Singh A, Mavalankar DV, Bhat R, Desai A, Patel SR, Singh PV, Singh N Providing skilled birth attendants and emergency obstetric care to the poor through partnership with private sector obstetricians in Gujarat, India. Bull World Health Organ. 2009;87:960-4.

18. Sidney K, lyer V, Vora K, Mavalankar D, De Costa A. Statewide program to promote institutional delivery in Gujarat, India: who participates and the degree of financial subsidy provided by the Chiranjeevi Yojana program. J Health Popul Nutr. 2016:35:2.

19. Size, Growth Rate and distribution of Population (Provisional Population Totals). Office of the Registrar General \& Census Commissioner, Ministry of Home Affairs, Governement of India. [http://censusindia.gov.in/]. Accessed Sept 2015.

20. Vital Statistics related to Health in Gujarat. Gender Resource Centre. State Resource Centre for Women, Gujarat, India. 2013-2014 [http://www. grcgujarat.org/pdf/I-t/b1-Vital-Statistics-related-to-health-in-Gujarat-2013-14. pdf]. Accessed Oct 2015.

21. National Family Health Survey (NFHS). International Institute for Population Sciences (IIPS), Mumbai, India, 2014-15. [http://iipsindia.org/research.htm]. Accessed Jan 2016.

22. Mohanty SK. Alternative wealth indices and health estimates in India. GENUS. 2009:65:113-37.

23. Harris PA, Taylor R, Thielke R, Payne J, Gonzalez N, Conde JG. Research electronic data capture (REDCap) - A metadata-driven methodology and workflow process for providing translational research informatics support. J Biomed Inform. 2009:42:377-81.

24. Government of Gujarat: Gujarat Social Infrastructure Development Board Society G. Evaluation of MCH Services in Gujarat: District Level Rapid Household Survey (DLRHS) Report-I. 2011.

25. Laxmaiah A, Brahmam GV, Meshram I, Rao K, Reddy C, Krishna K, Venkaiah K. Predictors of ante-natal care, delivery and infant feeding practices among rural women in Madhya Pradesh, India. Int J Med Public Health. 2014;4:385

26. Lim SS, Dandona L, Hoisington JA, James SL, Hogan MC, Gakidou E. India's Janani Suraksha Yojana, a conditional cash transfer programme to increase births in health facilities: an impact evaluation. Lancet. 2010;375:2009-23.

27. Bhimani N, Vachhani P, Girija Kartha SP. A study on awareness and utilization of "Chiranjeevi Yojana" among members of BPL families in the field practice area of rural health training centre (RHTC), Sayla of Surendranagar district. Int J Med Sci Public Health. 2013;2:819-23.

\section{Submit your next manuscript to BioMed Central and we will help you at every step:}

- We accept pre-submission inquiries

- Our selector tool helps you to find the most relevant journal

- We provide round the clock customer support

- Convenient online submission

- Thorough peer review

- Inclusion in PubMed and all major indexing services

- Maximum visibility for your research

Submit your manuscript at www.biomedcentral.com/submit
Biomed Central 